\title{
Synthesis of Aqueous Suspensions of Zero-Valent Iron Nanoparticles (nZVI) from Plant Extracts: Experimental Study and Numerical Modeling
}

\author{
Michalis Karavasilis a, b, Christos D. Tsakiroglou ${ }^{a^{*}}$ \\ ${ }^{a}$ Foundation for Research and Technology Hellas - Institute of Chemical Engineering Sciences, Stadiou str., Platani, 26504 Patras-Rio, Greece
}

${ }^{b}$ University of Patras, Department of Material Science, 26504 Patras, Greece

\begin{abstract}
Plant extracts were produced from Camellia sinesis (Green Tea) and Punica granatum (pomegranate), and the total concentration of polyphenols was measured in terms of equivalent concentration of Gallic acid by using the Folin-Ciocalteu method. Zero Valent Iron nanoparticles (nZVIs) were synthesized in a semi-batch reactor by mixing a pre-specified volume of plant extract or Gallic Acid solution with an aqueous solution of iron sulfate heptahydrate $\left(\mathrm{FeSO}_{4} \cdot 7 \mathrm{H}_{2} \mathrm{O}\right)$. To monitor the kinetics of nZVI synthesis, the transient responses of solution $\mathrm{pH}$ and redox potential (Eh) were recorded with two probes adequately connected with a data acquisition card. The nanoparticles were characterized by a variety of techniques: Dynamic Light Scattering (DLS), $\zeta$-potential, Attenuated Total Reflectance-Fourier Transform Infrared (ATR-FTIR) spectroscopy, Transmission Electron Microscopy (TEM). A kinetic parametric model, based on two parallel single electron transfer (SET) and hydrogen atom transfer (HAT) reactions, was suggested to quantify the dynamics of ferrous ions reduction to zero valence, and its parameters were estimated for each experimental system by matching the transient response of $\mathrm{pH}$. The temporal changes of redox potential during nZVI synthesis were indicative of the reaction progress and agreed with the numerical predictions in semi-quantitative basis. The numerical model enabled us to track the temporal variation of the concentration of iron and polyphenol species, and calculate the yield of ZVI synthesis. The reactivity of nZVIs was assessed by measuring their capacity to reduce hexavalent chromium $\mathrm{Cr}(\mathrm{VI})$ in aqueous solutions prepared from potassium dichromate $\left(\mathrm{K}_{2} \mathrm{Cr}_{2} \mathrm{O}_{7}\right)$.
\end{abstract}

Keywords:

Zero Valent Iron;

Nanoparticles;

Hexavalent Chromium;

Plant Extract;

Polyphenol;

Reaction Kinetics.

\section{Article History:}

Received: $\quad 17 \quad$ September 2019

Accepted: 12 November 2019

Published: 01 December 2019

\section{1- Introduction}

Nowadays, one of the main challenges is to restore and preserve the quality of soil and water. Many places all over the world face serious environmental problems, like the contamination of the subsurface, and the need for the remediation of soils and groundwater [1] Green chemistry is the layout of chemical products and approaches that lessen or remove the use of dangerous materials. The "greener" environmental techniques in chemistry are changing with progressively notable rates due to the stricter legislation concerning the environment and safety [2]. Among others, the use of nanotechnologies for environmental remediation has attracted funding and interest from the service companies and scientific society.

The term 'nanoremediation' refers to the reactivity of nano-scale materials for the transformation and detoxification of pollutants through chemical reduction and catalysis [3]. A great variety of nanomaterials have been tested in remediation studies, such as nanoscale semiconductor photocatalysts, carbon-based nanomaterials (carbon nanotubes CNT, fullerenes, graphene) bi-metallic nanoparticles. Among them, the Zero Valent Iron nanoparticles (nZVIs) has

\section{* CoNTACT: Ctsakir@iceht.forth.gr}

DOI: http://dx.doi.org/10.28991/esj-2019-01197

(C) 2019 by the authors. Licensee ESJ, Italy. This is an open access article under the terms and conditions of the Creative Commons Attribution (CC-BY) license (https://creativecommons.org/licenses/by/4.0/). 
widely been used for a long time, in a variety of environmental applications, as an excellent reducing agent, due to its inexpensive and nontoxic characteristics [4].

Nanoparticles are structures with physical size less than $100 \mathrm{~nm}$. The relatively small size allows them to be distributed better within colloid systems, and makes them more attractive to further research and industrial applications [5]. Also their high specific surface area makes them more reactive compared to larger particles of the same materials [6]. Generally, the synthesis of nanomaterials can be classified into two categories: bottom up and top-down [7]. Chemical vapor synthesis, sol-gel technique, electrodeposition, sputtering, mechanical attrition, chemical precipitation, colloidal chemistry are certain of the synthesis techniques [8]. Nevertheless, all aforementioned methods present a variety of problems in terms of cost and production of toxic byproducts (e.g. cogeneration of flammable hydrogen gas when synthesizing nZVI from sodium borohydride) throughout the process [9],[10]. A bottom-up approach for metal nanoparticles synthesis consists of the choice of the (i) solvent, (ii) reducing agent and (iii) capping agent [11]. In this manner, the size and shape of nanoparticles are governed by reaction conditions (e.g. pH, ORP, temperature) and the concentrations of raw materials. By 2009, the most popular technique for nZVIs synthesis was that based on the use of sodium borohydride as reducing agent, though adverse harmful impacts were caused on the environment [12].

Fruits, vegetables, herbs and grains (e.g. tea, grapes, and sorghum bran) contain high concentrations of polyphenols, so that plant extracts may act both as reducing agent of iron salt and as capping agent for iron nanoparticles. Beyond the high solubility, low toxicity and biodegradability of polyphenols, the advantages of this method of nZVI green synthesis at ambient temperature and pressure are the following: neither hazardous materials are used for the reductant or capping agent, nor any hazardous wastes are generated. Compared to other nZVI manufacturing processes, the resulting suspension is not undergone oxidative corrosion during its storage, shipping or use. This new synthetic method is an extremely simple green approach that generates bulk quantities of relatively stable nanocrystals of iron ( $\mathrm{Fe})$ using plant extract at room temperature. Hoag et al. (2009) published a scientific paper for the green synthesis of nZVI from green tea (Camelia Synesis) for bromothymol degradation [11]. Since then, several methods have been suggested [13-17] for the 'green' nZVI synthesis from plant extracts, for removing and degrading several contaminants in groundwater, including arsenate [18], dyes [19], phosphorus [19], and heavy metals [20]. Different compartments of a plant or its leaves present excellent properties, especially a high anti-oxidant capacity. Various compounds of plants like alkaloids, proteins, amino acids, phenolic acids, caffeine, and polyphenols play an important role in the "bio" reduction of metal ions. However, the key factor for the synthesis of nZVIs is the content of polyphenols which act both as reducing and capping agents. Ferric or ferrous iron is reduced to $\mathrm{Fe}^{0}$ by mixing the iron solution with the plant extract [21-23] Compared to other methods, the nZVI production from plant extracts satisfies the three main pillars of a green synthesis pathway: it is cost-effective, environmental friendly, and quite efficient [12].

In the present work, nZVI suspensions are synthesized from two types of extracts, Green Tea - GT (Camellia sinesis) and Pomegranate leaves-PG (Punica granatum), whereas a Gallic Acid (GA) solution is used as control system. The physicochemical and morphological properties of nZVI are determined by a variety of techniques, and its reactivity is assessed with respect to its capacity to reduce hexavalent chromium in aqueous solutions. A kinetic model based on two parallel reactions of hydrogen atom transfer (HAT) and single electron transfer (SET) is developed to quantify the dynamics of ferrous ions reduction to zero valent iron, and used to estimate the kinetic parameters with inverse modeling of the transient response of $\mathrm{pH}$, recorded during the nZVI synthesis. The model is used to compute the redox potential and concentration of all components involved in the reactions of iron reduction by polyphenols.

\section{2- Materials and Methods}

\section{2-1- Materials}

The following reagents were purchased and used without any purification: Sodium carbonate $\mathrm{Na}_{2} \mathrm{CO}_{3}$, Potassium dichromate $\mathrm{K}_{2} \mathrm{Cr}_{2} \mathrm{O}_{7}$ and Potassium nitrate $\mathrm{KNO}_{3}$ (Merck); Gallic acid $\mathrm{C}_{7} \mathrm{H}_{6} \mathrm{O}_{5}$, Iron (II) sulfate heptahydrate $\mathrm{FeSO} \cdot 7 \mathrm{H}_{2} \mathrm{O}$, Folin \& Ciocalteu's phenol reagent and Sulfuric acid, $\mathrm{H}_{2} \mathrm{SO}_{4}$ (Sigma-Aldrich). Deionized water (18.2M $\Omega$ $\mathrm{cm}^{-1}$ ) was prepared by a purification system (Milli-Q RG).

\section{2-2- Green Synthesis of $n Z V I$ Nanoparticles}

Fresh pomegranate leaves were collected from local trees, and green tea was purchased from thelocal market (Patras, Greece). Three distilled water (3DW) was used to prepare aqueous solutions of $\mathrm{Fe}^{2+}$ from ferrous sulfate heptahydrate $\mathrm{FeSO}_{4} \cdot 7 \mathrm{H}_{2} \mathrm{O}$. The pomegranate and green tea leaves were washed with $3 \mathrm{DW}$ for removing the dust and other undesirable substances, and then dried in an oven for 3 days at $45^{\circ} \mathrm{C}$. Moreover, the leaves were cut into pieces of size less than $0.5 \mathrm{~mm}$, to facilitate their handling and polyphenol extraction.

Green Tea GT-extract was prepared by heating an aqueous suspension of GT-leaves of concentration $50 \mathrm{~g} / \mathrm{L}$ (in dry weight basis) up to $80^{\circ} \mathrm{C}$ for $60 \mathrm{~min}$, and Pomegranate (Punica Granatum) PG-extract was prepared by heating an aqueous suspension of PG-leaves of concentration $35 \mathrm{~g} / \mathrm{L}$ (in dry weight basis) up to $80^{\circ} \mathrm{C}$ for $60 \mathrm{~min}$. 
The extracts were separated from the leaves by vacuum filtration through $0.8 \mu \mathrm{m}$ filter (Whatman) and centrifugation in $13000 \mathrm{rpm}$ for 20min (Heraeus Megafuge). The Total Polyphenol Content (TPC) of extracts was measured in terms of Gallic Acid Equivalent concentration (g/L GAE), by using the Folin-Ciocalteu method (ISO-14502-1) [24] and UVVis spectroscopy (HITACHI U-3000).

To synthesize nZVIs, PG-extract and GT-extract were added in $0.05 \mathrm{M}$ and $0.03 \mathrm{M} \mathrm{FeSO}_{4} \cdot 7 \mathrm{H}_{2} \mathrm{O}$ solutions for $60 \mathrm{~min}$ and $45 \mathrm{~min}$, respectively. The extract was injected with a peristaltic pump (Rainin) at constant flow rate equal to 4 $\mathrm{mL} / \mathrm{min}$, under continuous stirring at 700rpm, and co-injection of nitrogen. Simultaneously, the reaction progress was monitored by recording continuously the $\mathrm{pH}$ and Redox Potential (ORP), Eh, of the solution with two probes (Vernier $\mathrm{pH}$ and ORP electrodes) connected with a data acquisition card (LabQuest Steam) (Figure 1a). The experimental apparatus was placed in an incubator (Friocell) to keep constant temperature at $25^{\circ} \mathrm{C}$. The change of the solution colour from brownish yellow to black signifies the generation of zero valent iron particles (Figure 1b).
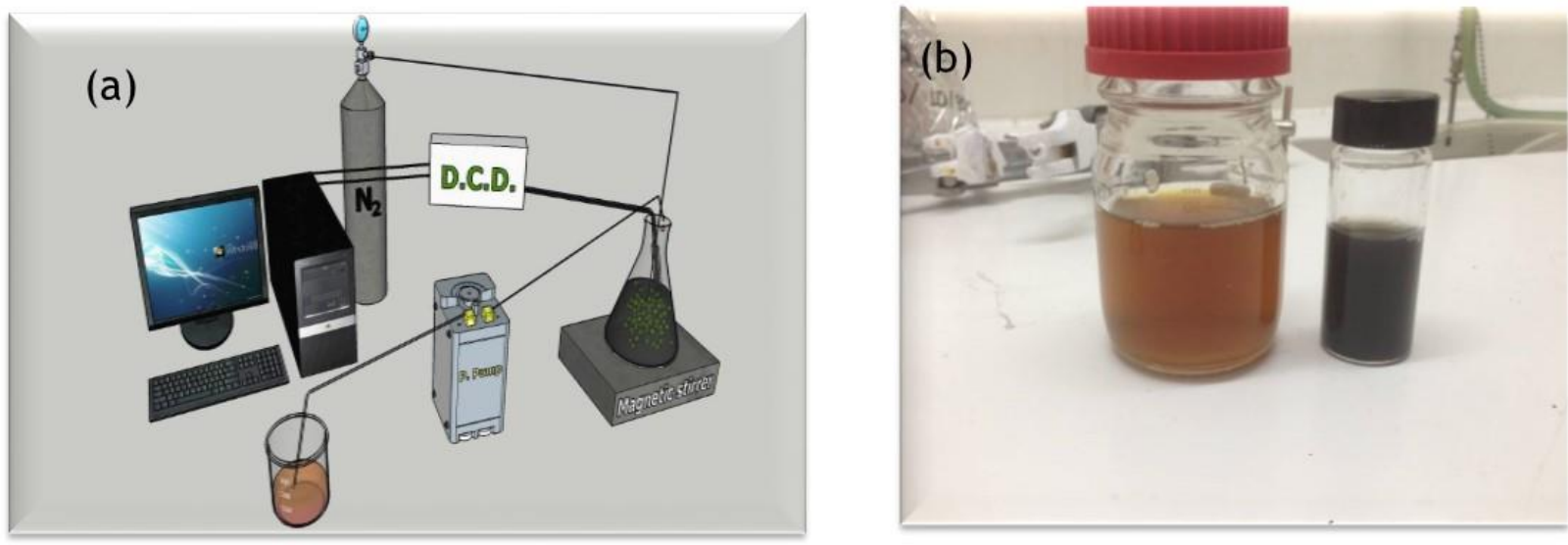

Figure 1. (a) Schematic diagram of the experimental setup; (b) Green Tea extract and its product after its mixing with $\mathrm{FeSO}_{4} \cdot 7 \mathrm{H}_{2} \mathrm{O}$

\section{2-3- Gallic Acid for the Synthesis of nZVI Nanoparticles}

To understand the role of polyphenols in the nZVI synthesis, a Gallic acid (GA) solution of concentration 68.6mM was prepared $\left(\mathrm{C}_{7} \mathrm{H}_{6} \mathrm{O}_{5}\right.$, Merck, Greece). Gallic acid is a phenolic compound that is known for its high antioxidant capacity, due to its three hydroxyl groups, while allowing for relatively straightforward copolymerization through its $\mathrm{COOH}$ group [25]. Gallic acid exists in plant material in the form of free acids, esters, catechin derivatives and hydrolysable tannins. This ubiquitous chemical substance is one of the most biologically-active phenolic compounds of plants [26]. Thus, a $0.1 \mathrm{M} \mathrm{FeSO}_{4} \cdot 7 \mathrm{H}_{2} \mathrm{O}$ solution was added in the Gallic acid solution, by the aforementioned procedure for a period of $30 \mathrm{~min}$.

\section{2-4- Batch Tests for Cr (VI) Reduction and nZVI Reactivity}

Batch experiments of hexavalent chromium reduction were conducted in duplicates in $250 \mathrm{ml}$ flasks. First, an aqueous solution $0.48 \mathrm{mM}$ of $\mathrm{K}_{2} \mathrm{Cr}_{2} \mathrm{O}_{7}$, containing $50 \mathrm{mg} / \mathrm{L}$ of $\mathrm{Cr}$ (VI), was prepared. In each flask, $95 \mathrm{ml}$ of solution containing $5 \mathrm{mg} / \mathrm{L} \mathrm{Cr}$ (VI) was mixed with nZVI suspensions of varying concenrtation to test their reduction efficiency. All tests were done inside an incubator at constant temperature of $25^{\circ} \mathrm{C}$, and under stirring at $600 \mathrm{rpm}$. Three values of mass ratio of total iron to $\mathrm{Cr}$ (VI) were tested. The concentration of $\mathrm{Cr}$ (VI) was measured by using the $7196 \mathrm{~A}$ Colorimetric Diphenylcarbazide Method [24].

\section{2-5- Material Characterization}

The morphological characterization of synthesized nZVI was done with Transmission Electron Microscope, TEM $(J E M-2100 ; 120 \mathrm{kV})$ at magnifications from $10,000 \times$ to $400,000 \times$. A drop of nZVI aqueous suspension was placed on a carbon film (C200Cu EMResolutions) and left for $30 \mathrm{~min}$ at room temperature to get dried.

The ATR-FTIR spectra of GT, PG, GA and GT-nZVI, PG-nZVI, GA-nZVI, were determined by Fourier transform infrared spectroscopy (FT-IR EQUINOX 55, Bruker Co.). All samples were heated on a hotplate at $50{ }^{\circ} \mathrm{C}$ for the evaporation of the liquid, and placed in an oven for 1 day at $45^{\circ} \mathrm{C}$, for the complete elimination of moisture.

The particle size distribution of suspended nZVIs was determined with Dynamic Light Scattering -DLS (Zetasizer Nano System, Malvern). Each nZVI sample was diluted at ratio 1:3000 with purified ethanol and left for half an hour to rest. Then, with the $\zeta$-Nanosizer (MALVERN), three measurements of the intensity-based particle-size distributions were recorded for each sample, during a period of $10 \mathrm{~min}$. Also, the $\zeta$-potential of nZVIs suspensions was measured with $\zeta$-Nanosizer by diluting each sample at ratio $1: 1000$ with $0.5 \mathrm{M} \mathrm{KNO}_{3}$. 


\section{3- Theoretical Modeling of nZVI Synthesis}

The statistics of metal $(\mathrm{Me}) /$ metal oxide $\left(\mathrm{Me}_{\mathrm{x}} \mathrm{O}_{\mathrm{y}}\right)$ nanoparticles, generated by mixing reactants in aqueous solution, is governed by the kinetics of the following mechanisms [27]: (a) chemical reactions of $\mathrm{Me} / \mathrm{Me}_{\mathrm{x}} \mathrm{O}_{\mathrm{y}}$ synthesis; (b) nucleation of $\mathrm{Me} / \mathrm{Me}_{\mathrm{x}} \mathrm{O}_{\mathrm{y}}$ particles and their growth by molecular diffusion; (c) interparticle coagulative-growth via oriented-attachment; (d) interparticle growth by Ostwald-ripening. However, in the present work we assume that the reactive process, (a), is the rate-controlling step for ZVI synthesis, and the mathematical model is restricted to the reactions kinetics.

\section{3-1- Kinetic Models of nZVI Synthesis}

Antioxidants like polyphenols can reduce radicals and metal ions by two major mechanisms: hydrogen atom transfer (HAT) and single electron transfer (SET) [28]. The end result is the same, regardless of mechanism, but kinetics and potential for side reactions differ. Proton-coupled electron transfer and HAT reactions may occur in parallel, and the mechanism dominating in a given system will be determined by antioxidant structure and properties, solubility and partition coefficient, and system solvent. We consider that the reduction of divalent iron cations, $\mathrm{Fe}^{2+}$, by polyphenol molecules, AH, may be described through two parallel mechanisms of single electron transfer.

$$
\mathrm{Fe}^{2+}+2 \mathrm{AH} \stackrel{k_{1}}{\rightarrow} \mathrm{Fe}^{0}+2 \mathrm{AH}
$$

And hydrogen atom transfer

$$
F e^{2+}+2 A H \stackrel{k_{2}}{\rightarrow} F e^{0}+2 A^{*}+2 H^{+}
$$

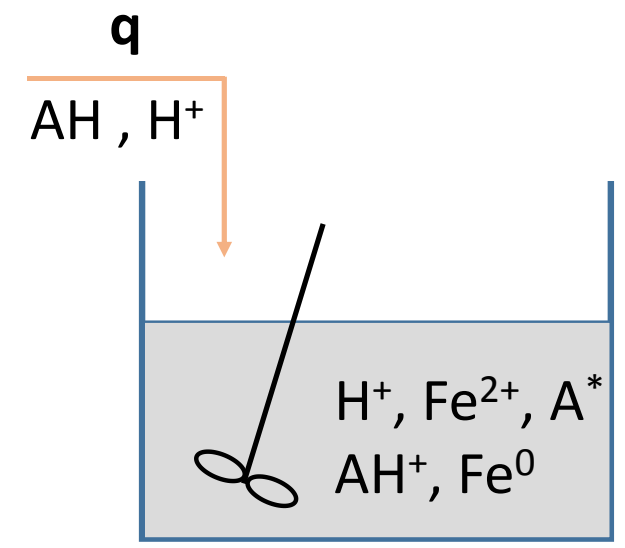

Figure 2. Simplified representation of a semi-batch reactor, where the polyphenol solution is injected in the iron salt solution.

For reactions (1) and (2), we assume that the consumption rate of ferrous ions and polypehnols, quantified as the $1^{\text {st }}$ time derivative of their molar concentration, can be described by the general models

$$
\frac{d\left[C_{F e^{2+}}\right]}{d t}=\frac{1}{2} \frac{d\left[C_{A H}\right]}{d t}=-k_{1}\left[C_{F e^{2+}}\right]^{m_{1}}\left[C_{A H}\right]^{l_{1}}
$$

And

$$
\frac{d\left[C_{F e^{2+}}\right]}{d t}=\frac{1}{2} \frac{d\left[C_{A H}\right]}{d t}=-k_{2}\left[C_{F e^{2+}}\right]^{m_{2}}\left[C_{A H}\right]^{l_{2}}\left[C_{H^{+}}\right]^{-n_{d}}
$$

Respectively, where $\left[C_{i}\right]$ denotes the molar concentration $\left(\mathrm{kmol} / \mathrm{m}^{3}\right)$ of the component $i, k_{i}$, is the kinetic constant of reaction $i$, and $m_{i}, l_{i}, n_{d}$ are positive exponents. The last term in the right-hand side of Equation 4 indicates that the rate of reaction (2) is suppressed by the high proton concentration, and gradually, at sufficiently low pH values, this reaction rate is expected to cease. If the molar concentrations $\left[C_{i}\right]$ are converted into mass concentrations $C_{i}\left(\mathrm{~kg} / \mathrm{m}^{3}\right)$ by incorporating the molecular weights $M W_{i}$ of components into new kinetic constants, $k_{r 1} k_{r 2}$, and mass balances are applied to each component of the experimental semi-batch reactor, shown in Figure 2, we obtain:

$$
\begin{aligned}
& \frac{d C_{F e^{2+}}}{d t}=-\frac{q}{V} C_{F e^{2+}}-M W_{F e}\left(k_{r 1} C_{F e^{2+}}{ }^{m_{1}} C_{A H}{ }^{l_{1}}+k_{r 2} C_{F e^{2+}}{ }^{m_{2}} C_{A H}{ }^{l_{2}} C_{H^{+}}{ }^{-n_{d}}\right) \\
& \frac{d C_{A H}}{d t}=-\frac{q}{V} C_{A H}-2 M W_{A H}\left(k_{r 1} C_{F e^{2+}}{ }^{m_{1}} C_{A H}{ }^{l_{1}}+k_{r 2} C_{F e^{2+}}{ }^{m_{2}} C_{A H}{ }^{l_{2}} C_{H^{+}}{ }^{-n_{d}}\right)+\frac{q}{V} C_{A H, i n} \\
& \frac{d C_{A H^{+}}}{d t}=-\frac{q}{V} C_{A H^{+}}+2 M W_{A H} k_{r 1} C_{F e^{2+}}{ }^{m_{1}} C_{A H}{ }^{l_{1}}
\end{aligned}
$$




$$
\begin{aligned}
& \frac{d C_{A^{*}}}{d t}=-\frac{q}{V} C_{A^{*}}+2 M W_{A^{*}} k_{r 2} C_{F e^{2+}}{ }^{m_{2}} C_{A H}{ }^{l_{2}} C_{H^{+}}{ }^{-n_{d}} \\
& \frac{d C_{H^{+}}}{d t}=-\frac{q}{V} C_{H^{+}}+2 M W_{H} k_{r 2} C_{F e^{2+}}{ }^{m_{2}} C_{A H}{ }^{l_{2}} C_{H^{+}}{ }^{-n_{d}}+\frac{q}{V} C_{H^{+}, i n} \\
& \frac{d C_{F e}^{0}}{d t}=-\frac{q}{V} C_{F e^{0}}+M W_{F e}\left(k_{r 1} C_{F e^{2+}}{ }^{m_{1}} C_{A H}{ }^{l_{1}}+k_{r 2} C_{F e^{2+}}{ }^{m_{2}} C_{A H}{ }^{l_{2}} C_{H^{+}}{ }^{-n_{d}}\right)
\end{aligned}
$$

Where $C_{i, i n}$ is the mass concentration of component $i$ in injected solution, $q$ is the flow rate $\left(\mathrm{m}^{3} / \mathrm{s}\right)$ of injected solution, and $V$ is the total volume of solution in reactor $\left(\mathrm{m}^{3}\right)$, given by the relations:

$$
\begin{aligned}
& \frac{d V}{d t}=q t \quad \text { if } t \leq t_{i n j} \\
& \frac{d V}{d t}=0 \quad \text { if } t>t_{i n j}
\end{aligned}
$$

Where $t_{i n j}$ is the duration of solution injection.

To calculate the redox potential under non-standard conditions, $E_{h}$, the Nerst equation is used

$$
E h=E h^{0}-\left(\frac{R T}{n F}\right) \ln Q_{i}
$$

Where $E h^{0}$ is the standard redox potential, $R$ is the universal gas constant $(=8.31 \mathrm{~J} / \mathrm{mole} \mathrm{K}), T$ is the absolute temperature $(=298 \mathrm{~K}), F$ is the Faraday's constant ( $=96485 \mathrm{C} /$ mole $\left.\mathrm{e}^{-}\right), n$ is the number of electrons transferred in overall reaction $(\mathrm{n}=2)$, and $Q_{i}$ is the reaction quotient which could be approximated by the relation:

$$
Q_{i}=\frac{\left\{\left[C_{H^{+}}\right]+\left[C_{\mathrm{AH}^{+}}\right]\right\}^{2}}{\left[C_{\mathrm{Fe}^{2+}}\right]}
$$

To calculate the fraction numerator of Equation 13, the molar concentrations of ion species generated by mechanistic reaction steps, Equations 1 and 2, are added, while any other species that might affect the reaction quotient are ignored. A high uncertainty might be embedded in Equation 13, and for this reason we preferred to ignore the transient response of $E h$ in parameter estimation. However, the post-calculated response of $E h$ at optimal parameter values, could be compared with the corresponding measured response.

The system of ordinary differential equations (ODEs), Equations 5 to 11, can be solved numerically by setting the initial concentrations of compounds equal to those of aqueous solutions used in nZVI synthesis. For the numerical solution of ODEs, the software package Athena Visual Studio was utilized [29]. The coupled ODEs were solved using the solver DDAPLUS, that employs a variable-order, variable-step predictor-corrector approach, and combines a modified Newton algorithm with a fixed leading coefficient backward difference formula for the approximation of the first order time derivative [29]. The non-linear estimation of kinetic parameters quantifying the nZVI synthesis was done by matching the numerically calculated ratio, $\mathrm{pH} / \mathrm{pH}(\mathrm{t}=0)$, to its transient response measured during the experiment. To achieve this goal, the Bayesian estimator of the GREGPLUS solver of Athena Visual Studio was adapted to the numerical solution of DDAPLUS solver. The minimization problem was solved with successive quadratic programming, starting from the initial guesses of parameters, using a modified Gauss-Jordan algorithm, and conducting a weak line search to establish an improved objective value and initial parameter vector for the next iteration [29].

\section{3-2- Kinetics of $\mathrm{Cr}$ (VI) Reduction by $\mathrm{nZVI}$}

Considering that the reduction of Cr (VI) by nZVI is approximated by a $2^{\text {nd }}$ order reaction of the form

$$
\begin{aligned}
& \frac{d C_{c r(V I)}}{d t}=-M W_{C r} k_{r, C r} C_{C r(V I)} C_{F e^{0}} \\
& \frac{d C_{F e}^{0}}{d t}=-M W_{F e} k_{r, C r} C_{C r(V I)} C_{F e^{0}}
\end{aligned}
$$

Then, for estimating the kinetic constant, $k_{r, C r}$, for each reaction system (GT-nZVI, PG-nZVI, GA-nZVI) the Cr(VI) concentration as a function of time, obtained from the numerical solution of the ODEs, Eqs.(14a), (14b), was fitted to corresponding experimental measurements for various initial values of nZVI concentration, with the aid of the Athena Visual Studio software package. 


\section{4- Results and Discussion}

\section{4-1- Characterization of Plant Extracts}

The extracts of Green Tea (GT) and Pomegranates Leaves (PG) were characterized by measuring their Total Polyphenol Content (TPC), pH, and Redox Potential (Eh). The TPC is proportional to the mass of the raw material and duration of extraction, and the characteristics of produced polyphenol solutions are shown in Table 1.

Table 1. Physicochemical properties of plant extracts and Gallic acid solution.

\begin{tabular}{cccc}
\hline & PH & EH (MV) & TPC $($ G-GAE/L) \\
\hline Green Tea (GT) & 5.05 & 167 & 5.24 \\
Pomegranate (PG) & 4.26 & 300 & 7.06 \\
Gallic Acid (GA) & 2.65 & 295 & 11.7 \\
\hline
\end{tabular}

\section{4-2- Reaction Patterns and Properties of nZVI}

The green synthesis of $\mathrm{Fe}^{0}$ nanoparticles was confirmed by the sharp change of the initially colorless ferrous sulfate solution to black, thus signaling the generation of metallic iron. The chemical reaction of reducing the ferrous iron to zero valence could be approximated by two parallel reactions, Equations 1 and 2.

The simultaneous measurements of $\mathrm{pH}$ and $\mathrm{Eh}$ as functions of time allows a detailed inspection of the kinetics of the synthesis reaction (Figure 3) by two ways: (1) On the one hand, these responses could be regarded as a 'pattern' of the transient evolution of reaction, and used as quantitative criterion for either the comparative analysis of different nZVI synthesis "recipes" or the correlation of the reaction conditions with the properties of nZVIs (pattern recognition). (2) On the other hand, these responses are experimental data which, in combination with kinetic models of the relevant processes that take place, Equations 5 to 11, could be exploited to estimate kinetic parameters of the nZVI synthesis reaction. The reduction of iron occurs as soon as the extract is mixed with iron salt solution, and this is indicative of the strong reduction capacity of polyphenols. The drop of the redox potential, Eh (Figure 3b, d, f) is associated with the reductive reaction occurring when the extract is mixed with the iron solution $\left(\mathrm{FeSO}_{4}\right)$, and confirms the creation of elemental iron $\mathrm{Fe} 0$. The low $\mathrm{pH}$ of the mixture prevents the oxidation of nZVIs and facilitates their longevity, and reactivity with pollutants. The properties of the initial solution and final nZVI suspension are shown in Table 2.
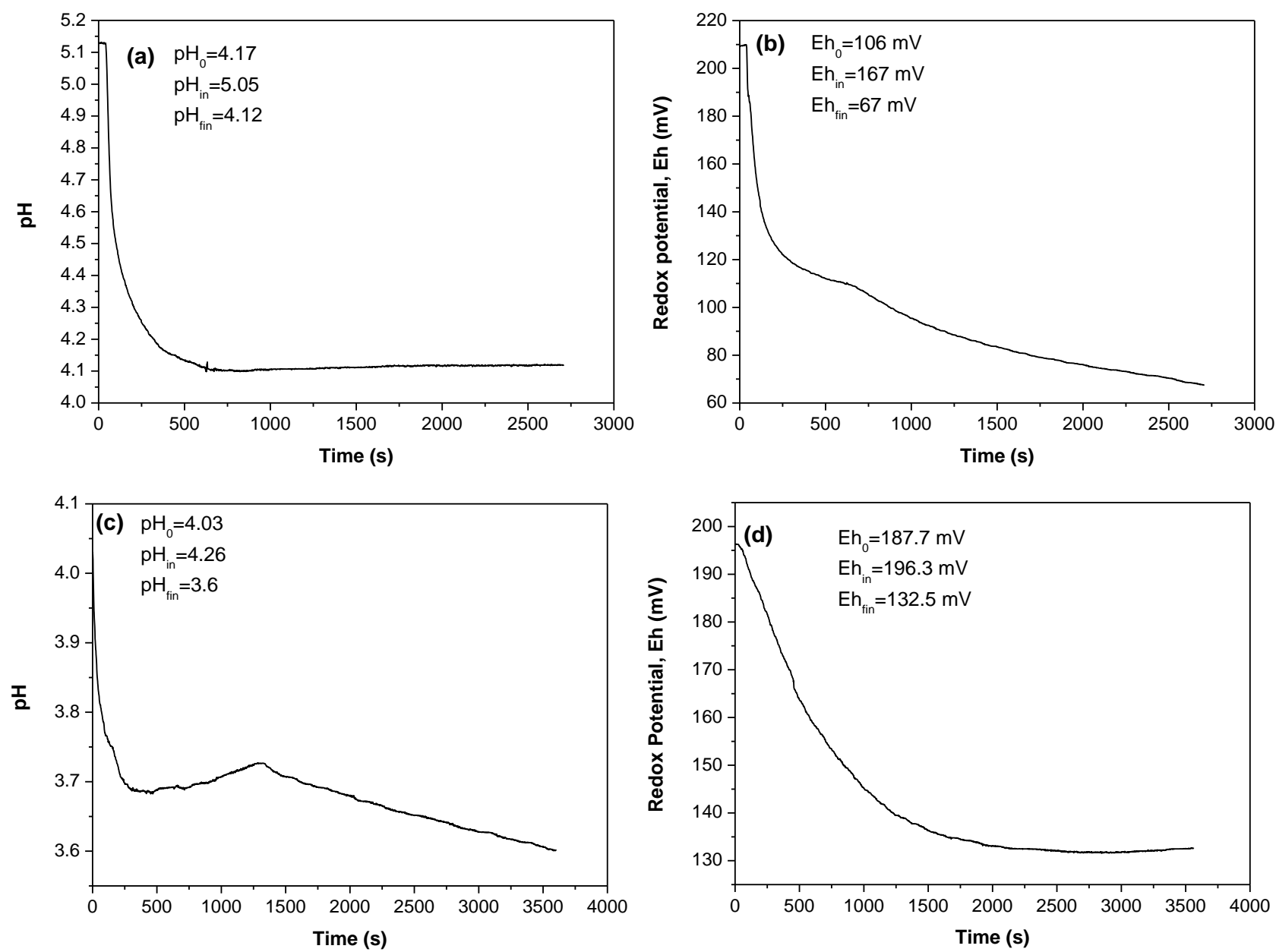

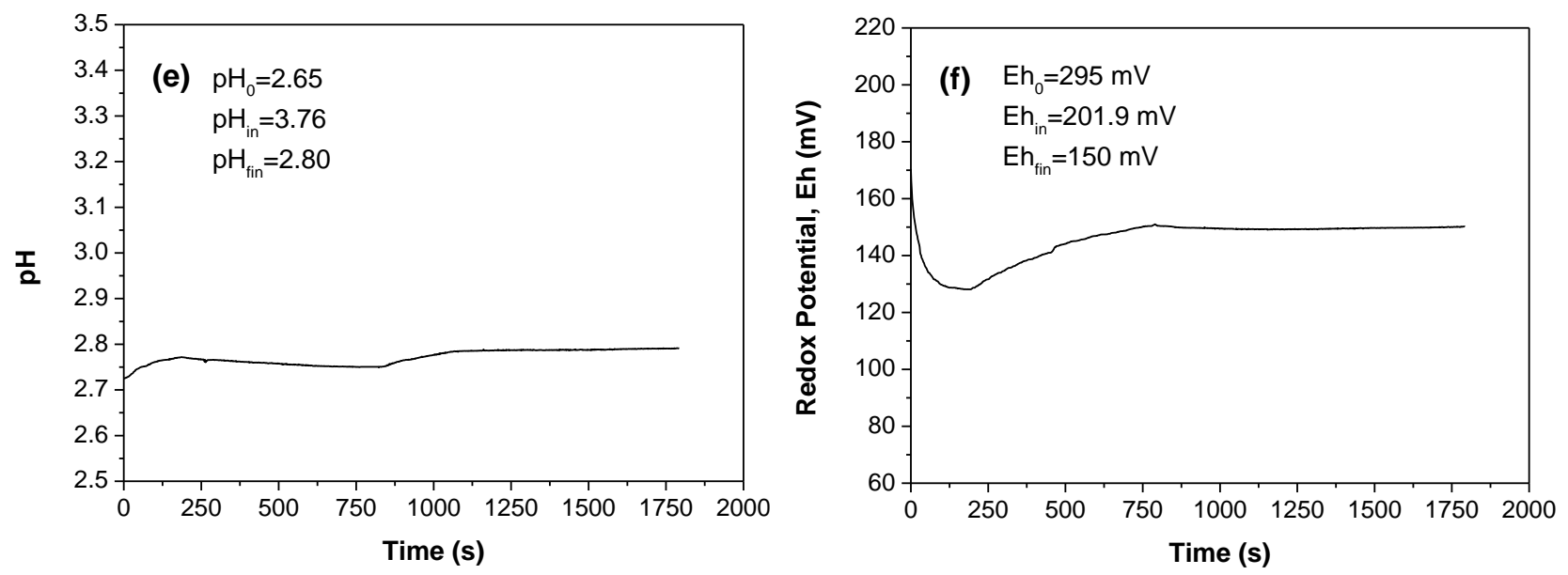

Figure 3. Transient response of (a, c, e) pH, and (b,d,f) Redox Potential, Eh, during the synthesis of nZVI suspensions by injecting (a,b) Green Tea (GT) extract in $\mathrm{FeSO} 4 \cdot 7 \mathrm{H}_{2} \mathrm{O}$ solution, (c,d) Pomegranate (PG) extract in FeSO4· $7 \mathrm{H}_{2} \mathrm{O}$ solution, (e,f) $\mathrm{FeSO} \cdot 7 \mathrm{H}_{2} \mathrm{O}$ solution in Gallic Acid (GA) solution.

Table 2. Physicochemical properties of initial solution and final nZVI suspension.

\begin{tabular}{cccccccc}
\hline \multirow{2}{*}{ Polyphenol Solution } & \multicolumn{3}{c}{ Initial Ferrous Solution $(\mathbf{T}=\mathbf{0})$} & & \multicolumn{2}{c}{ Final Nzvi Suspension } \\
\cline { 2 - 4 } \cline { 6 - 7 } & $\mathbf{p H}_{\mathbf{0}}$ & $\mathbf{E h}_{\mathbf{0}}(\mathbf{m V})$ & $\mathbf{C}_{\mathbf{F e}}(\mathbf{g} / \mathbf{L})$ & & $\mathbf{p H}$ & $\mathbf{E h}(\mathbf{m V})$ \\
\hline Green Tea (GT) & 4.17 & 106 & 1.69 & & 4.12 & 67.5 \\
Pomegranate (PG) & 4.03 & 187.7 & 2.80 & & 3.60 & 132.5 \\
Gallic Acid (GA) & 2.65 & 295.0 & 5.58 & & 2.80 & 150.0 \\
\hline
\end{tabular}

The particle size distributions along with the average diameter and $\zeta$-potential of nZVI suspensions, all measured with $\zeta$-Nanosizer, are shown in Figure 4. The negative values of $\zeta$-potential confirm the high stability of the system [30]. On the other hand, the relatively high values of particle sizes might be attributed to assemblages of polyphenols surrounding the nanoparticles. This becomes clear, if one looks at TEM images (Figure 5), and the statistics of the particle size distributions obtained with image analysis (Figure 6). It seems that the largest ZVI nanoparticles are produced when using Gallic acid as polyphenol solution (Figures 5c and 6c). The diversity of particles sizes (Figures 5 and 6), depending on the origin of polyphenol solution and sequence of solutions mixing, could be attributed to the different 'reaction pattern', as quantified by the transient response of $\mathrm{pH}$ and Eh of reacting systems (Figure 3). It is worth mentioning that smaller nZVI particles are created when the polyphenol mixture of plant extract is added in the ferrous solution (Figures $5 \mathrm{a}$ and $5 \mathrm{~b}$ ) rather than when $\mathrm{FeSO}_{4} \cdot 7 \mathrm{H}_{2} \mathrm{O}$ solution is added in Gallic Acid solution (Figure $5 \mathrm{c}$ ). On the other hand, in the one case, $\mathrm{pH}$ and Eh decrease almost monotonically with the time (Figures 3a, 3b, 3c and 3d), while in the other case, $\mathrm{pH}$ remains almost unaltered and $\mathrm{Eh}$ is stabilized quickly (Figures $3 \mathrm{e}$ and $3 \mathrm{f}$ ).
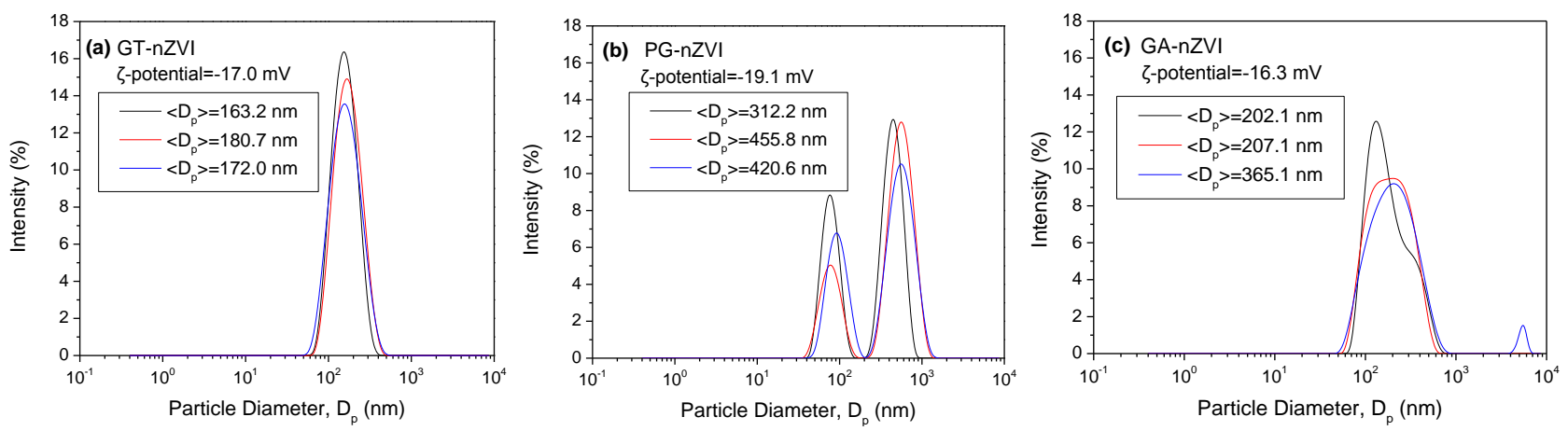

Figure 4. DLS-measured size distributions of suspended nZVI particles. For each diluted aqueous sample, three (3) measurements of the particle size statistics are done. (a) GT-nZVI; (b) PG-nZVI; (c) GA-nZVI. 

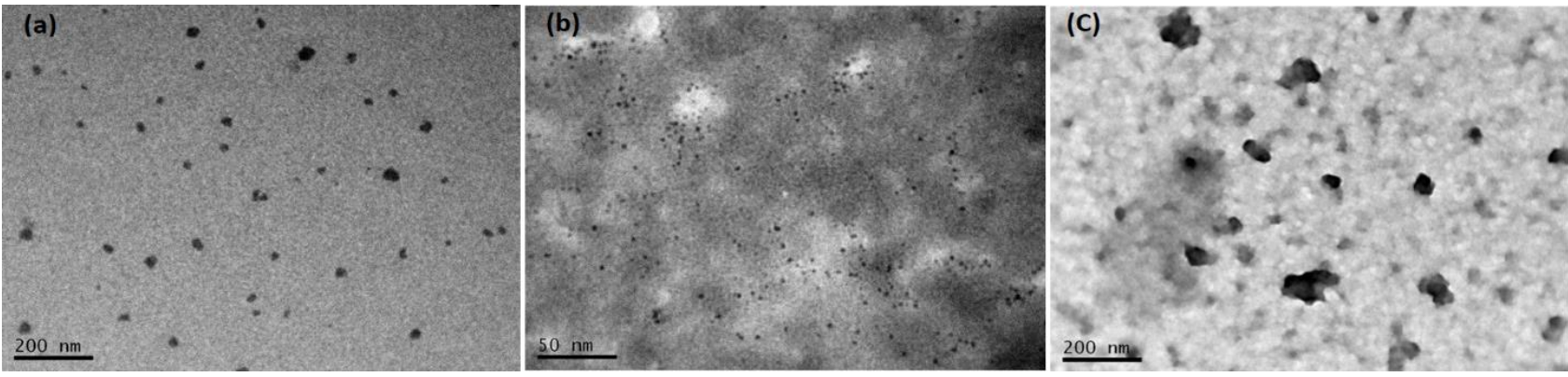

Figure 5. TEM images of (a) GT-nZVI, (b) PG-nZVI, (c) and (d) GA-nZVI.
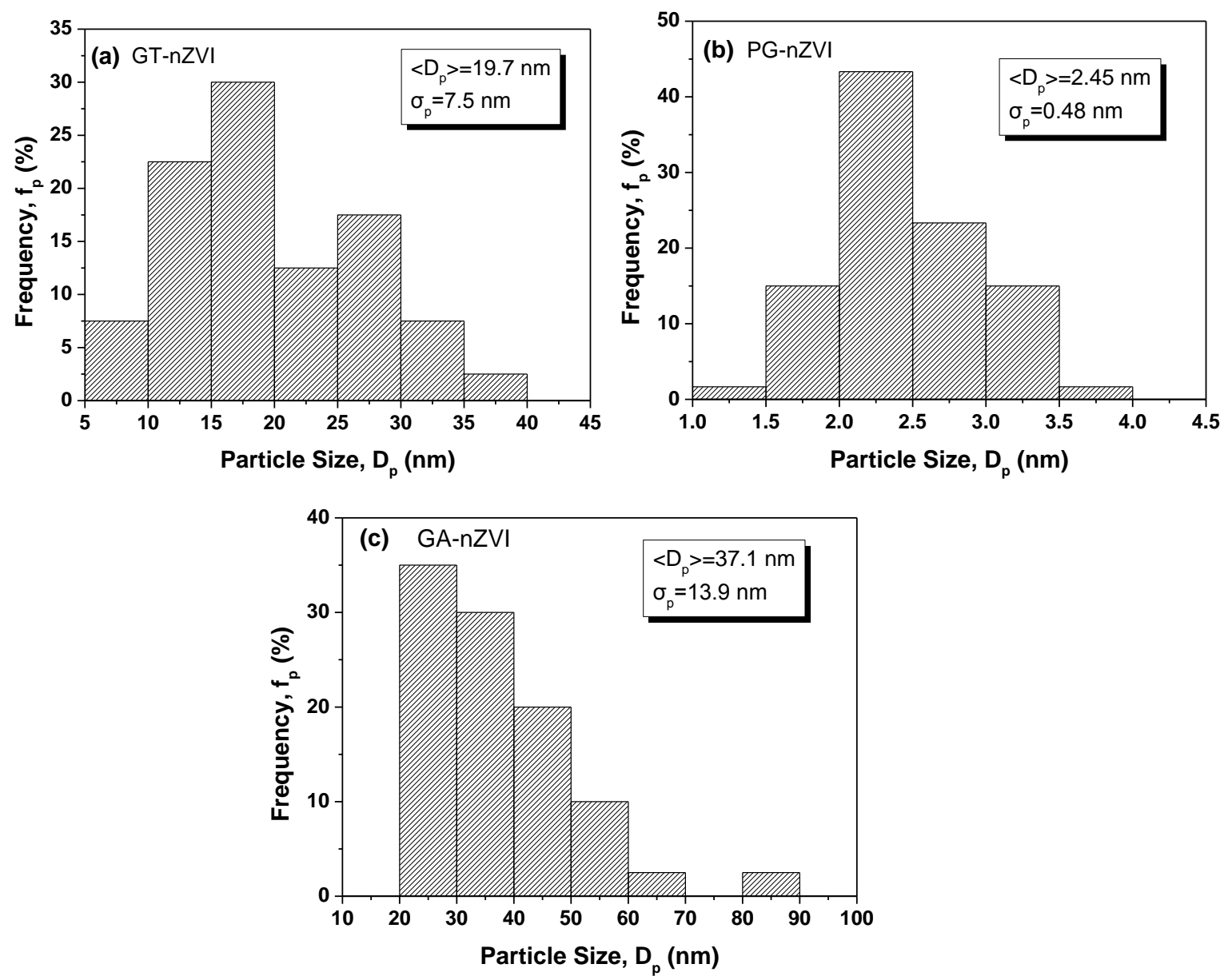

Figure 6. Statistics of the nanoparticle size distributions measured with analysis of TEM images: (a) GT-nZVI, (b) PGnZVI, (c) GA-nZVI.

ATR-FTIR spectra of plant extracts, Gallic acid and synthesized nZVIs were analyzed to identify the biomolecules which act as capping and stabilizing agents of nanoparticles. All these spectra are shown in Figure 7. In general, all nZVI spectra indicated the same wavenumber band (peaks) with that of the capping agent (extracts and gallic acid). For the GT extract and nZVI, a strong band appears at $3297 \mathrm{~cm}^{-1}$ that is assigned to O-H stretching vibrations (phenols). The peak at $1636 \mathrm{~cm}^{-1}$ was derived from $\mathrm{C}=\mathrm{O}$ stretches (where polyphenols and flavonoids appear), and the bands at 1610 correspond to $\mathrm{C}=\mathrm{C}$ where aromatic rings are present (Figure 7a). Aromatic and aliphatic amines $\mathrm{C}-\mathrm{N}$ are also present in GT at $1340 \mathrm{~cm}^{-1}$ and $1041 \mathrm{~cm}^{-1}$, respectively $[15,31,32]$. PG extract and nZVI indicated similar spectra with GT (Figure 7b). Hydroxyl and phenols, O-H stretches appear at $3270 \mathrm{~cm}^{-1}$ wavenumbers, whereas a peak at $2931 \mathrm{~cm}^{-1}$ refers to $\mathrm{C}-\mathrm{H}$ methylene groups (Figure $7 \mathrm{~b}$ ). Both in $\mathrm{GT}$ and $\mathrm{PG}$, carboxyl groups $\mathrm{C}=\mathrm{O}, \mathrm{C}=\mathrm{C}$ aromatic rings and $\mathrm{C}-\mathrm{N}$ amines appear at $1694 \mathrm{~cm}^{-1}, 1612 \mathrm{~cm}^{-1}, 1338 \mathrm{~cm}^{-1} 1035 \mathrm{~cm}^{-1}$ wavenumbers, respectively (Figures 7a and 7b) [33-35]. In GA and GA-nZVI, the broad band in $3259 \mathrm{~cm}^{-1}$ is assigned to $\mathrm{OH}$ functional groups (Figure 7c), exactly like the GT and $\mathrm{PG}$ extracts. The presence of sharp peak at $1612 \mathrm{~cm}^{-1}$ refers to $\mathrm{C}=\mathrm{C}$ aromatic ring. Moreover, the peaks among 1201 $\mathrm{cm}^{1}$ and $1311 \mathrm{~cm}^{-1}$ wavenumbers represent the $\mathrm{C}-\mathrm{O}$ deformation vibration of phenols and carboxyl. $\mathrm{Cyclic}$ alcohols $\mathrm{CH}-$ $\mathrm{O}-\mathrm{H}$ vibrations appear in $1022 \mathrm{~cm}^{-1}$ [35-36]. 

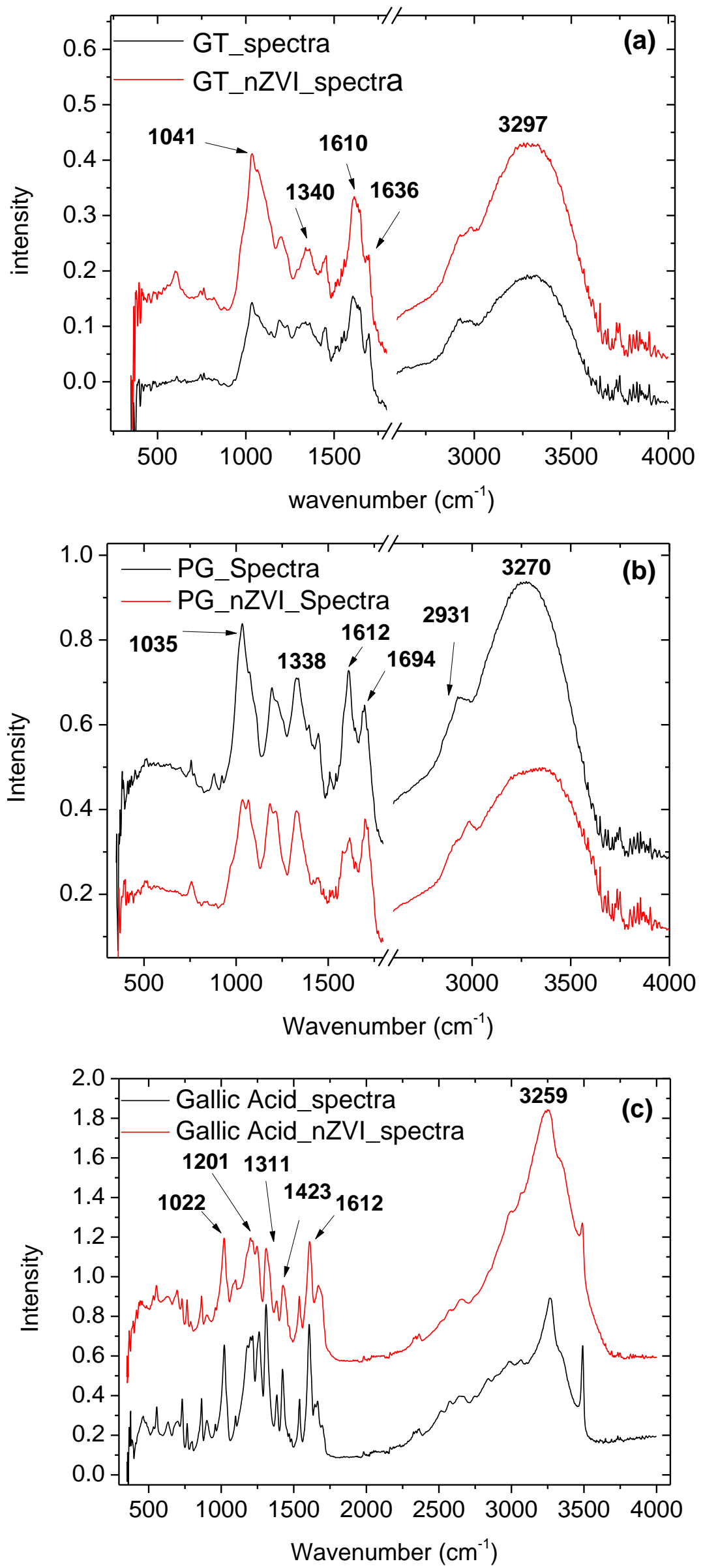

Figure 7. ATR-FTIR spectra of: (a) GT and GT-nZVI; (b) PG and PG-nZVI; (c) GA and GA-nZVI. 


\section{4-3- Hexavalent Chromium Reduction}

The reactivity of nZVI was measured by its capacity to reduce hexavalent chromium $\mathrm{Cr}(\mathrm{VI})$ in aqueous solutions. The reduction reaction of $\mathrm{Cr}(\mathrm{VI})$ could be described by the following equation:

$$
\mathrm{Fe}^{0}+\mathrm{HCrO}_{4}^{-}+7 \mathrm{H}^{+} \rightarrow \mathrm{Fe}^{3+}+\mathrm{Cr}^{3+}+4 \mathrm{H}_{2} \mathrm{O}
$$

The results of $\mathrm{Cr}(\mathrm{VI})$ reduction by nZVIs are shown in Figure 8. At the Fe/Cr mass ratio increases, the rate of $\mathrm{Cr}$ (VI) reduction increases for both types of nZVIs (GT and PG) (Figures 8a and 8b) and the reaction seems to be completed after $\sim 20 \mathrm{hr}$. The $\mathrm{Cr}(\mathrm{VI})$ reduction by GA-nZVI was so fast that the concentration of $\mathrm{Cr}$ (VI) dropped rapidly below the detection limit, and we were unable to track the rate of $\mathrm{Cr}$ (VI) concentration change at high $\mathrm{Fe} / \mathrm{Cr}$ mass ratios (Figure 8c).
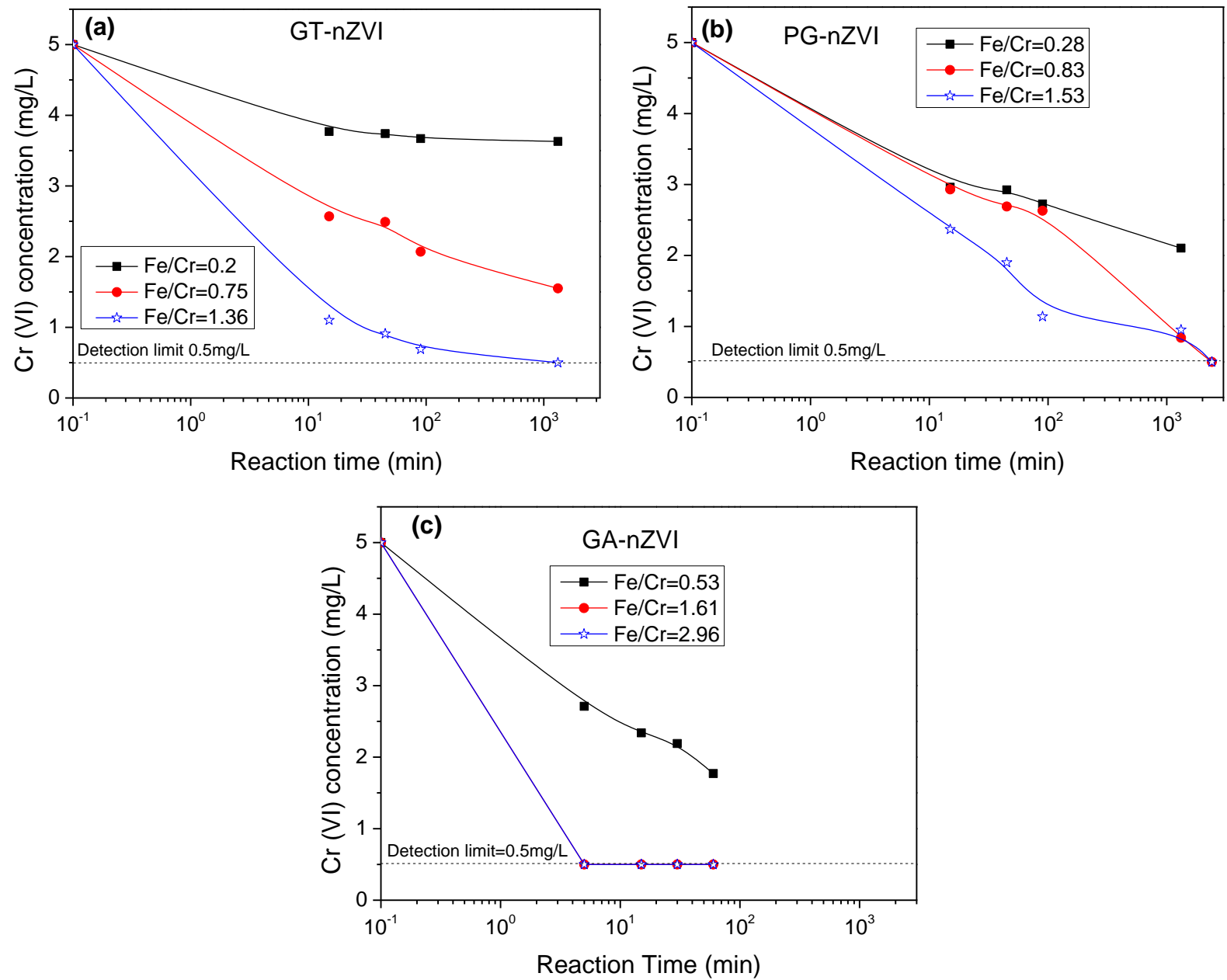

Figure 8. Kinetics of the hexavalent chromium reduction by (a) GT-nZVI, (b) PG-nZVI (c) GA-nZVI.

\section{4-5- Parameter Estimation and Reaction Efficiency}

The parameter values and confidence intervals (Table 4) for GT-nZVI (Figure 9a), PG-nZVI (Figure 10a), and GAnZVI (Figure 11a) synthesis were estimated with the numerical solution of Equations 5 to 11 by using the initial conditions and parameter values shown in Table 3 , and fitting the calculated transient response of $\mathrm{pH} / \mathrm{pH}_{0} \mathrm{ratio}$ to experimentally measured results (Figures 3a, 3c and 3e). An average value $M W_{A H}=320 \mathrm{~g} / \mathrm{mol}$ was set for the molecular weight of polyphenols of plant extracts (GT, PG), based on the concentration distribution of polyphenol compounds in green tea extracts from literature [37]. The temporal variation of $\mathrm{pH}$ is predicted with excellent precision by the numerical model at estimated parameter values, for GT-nZVI and PG-nZVI (Figures 9a and 10a), while some discrepancy is observed for GA-nZVI (Figure 11a), though in this case, changes of the $\mathrm{pH} / \mathrm{pH}_{0}$ ratio occur over a narrow range (Figure 11a). Moreover, the transient response of the redox potential was computed by Equations 12 and 13, and compared with experimental results (Figures $9 \mathrm{~b}, 10 \mathrm{~b}$ and $11 \mathrm{~b}$ ). The standard redox potential, $E h^{0}$, was so selected that Equations 12 and 13 were valid at the initial time $t=0$. Evidently, though the predicted response of $E h / E h_{0}$ agrees qualitatively with the observed variation of this parameter (Figures $9 \mathrm{~b}, 10 \mathrm{~b}$ and 11b), there is a clear discrepancy between predicted and measured responses, in quantitative basis, since, as mentioned earlier, the experimental measurements of 
$E h / E h_{0}$, were not accounted for parameter estimation, due to uncertainties associated with the accurate computation of reaction quotient, Equation 13.

Table 3. Initial conditions and parameter values used in simulations.

\begin{tabular}{|c|c|c|c|}
\hline Variable & GT-nZVI & PG-nZVI & GA-nZVI \\
\hline $\boldsymbol{V}(\boldsymbol{t}=\mathbf{0})(\mathrm{mL})$ & 40.0 & 30.0 & 30.0 \\
\hline $\boldsymbol{C}_{\boldsymbol{F} e^{2+}}(\boldsymbol{t}=\mathbf{0})(\mathrm{g} / \mathrm{L})$ & 1.69 & 2.8 & 0.0 \\
\hline $\boldsymbol{C}_{\boldsymbol{A} \boldsymbol{H}}(\boldsymbol{t}=\mathbf{0})(\mathrm{g} / \mathrm{L})$ & 0.0 & 0.0 & 11.7 \\
\hline $\boldsymbol{C}_{\boldsymbol{H}^{+}}(\boldsymbol{t}=\mathbf{0})(\mathrm{g} / \mathrm{L})$ & $10^{-5.13}$ & $10^{-4.03}$ & $10^{-2.65}$ \\
\hline $\boldsymbol{C}_{\boldsymbol{A} \boldsymbol{H}^{+}}(\boldsymbol{t}=\mathbf{0})(\mathrm{g} / \mathrm{L})$ & 0.0 & 0.0 & 0.0 \\
\hline $\boldsymbol{C}_{\boldsymbol{A}^{*}}(\boldsymbol{t}=\mathbf{0})(\mathrm{g} / \mathrm{L})$ & 0.0 & 0.0 & 0.0 \\
\hline$C_{F e^{0}}(t=0)(\mathrm{g} / \mathrm{L})$ & 0.0 & 0.0 & 0.0 \\
\hline$p H_{0}=p H(t=0)$ & 5.13 & 4.03 & 2.65 \\
\hline $\boldsymbol{E} \boldsymbol{h}_{\mathbf{0}}=\boldsymbol{E} \boldsymbol{h}(\boldsymbol{t}=\mathbf{0})(\mathrm{mV})$ & 106 & 187 & 295 \\
\hline$p H_{\text {in }}$ & 5.05 & 4.26 & 3.76 \\
\hline $\boldsymbol{E} \boldsymbol{h}_{\boldsymbol{i n}}(\mathrm{mV})$ & 167 & 299 & 201.9 \\
\hline $\boldsymbol{C}_{\boldsymbol{H}^{+}, \boldsymbol{i n}}(\mathrm{g} / \mathrm{L})$ & $10^{-5.05}$ & $10^{-4.26}$ & $10^{-3.76}$ \\
\hline$C_{A H, \text { in }}(\mathrm{g} / \mathrm{L})$ & 5.24 & 7.06 & 0.0 \\
\hline $\boldsymbol{C}_{F e^{2+}, \text { in }}(\mathrm{g} / \mathrm{L})$ & 0.0 & 0.0 & 5.58 \\
\hline $\boldsymbol{t}_{\boldsymbol{i n j}}(\min )$ & 37.5 & 23.0 & 12.5 \\
\hline $\boldsymbol{q}(\mathrm{mL} / \mathrm{min})$ & 4.0 & 4.0 & 2.0 \\
\hline$M W_{A H}$ & 320.0 & 320.0 & 170.1 \\
\hline
\end{tabular}

Table 4. Estimated parameter values and confidence intervals.

\begin{tabular}{cccc}
\hline Parameter & GT-nZVI & PG-nZVI & GA-nZVI \\
\hline $\boldsymbol{k}_{\boldsymbol{r} \mathbf{1}}$ & $2.668 \times 10^{-5} \pm 6.473 \times 10^{-7}$ & $1.1829 \times 10^{-5} \pm 5.45 \times 10^{-6}$ & $2.4305 \times 10^{-6} \pm 1.99 \times 10^{-7}$ \\
$\boldsymbol{m}_{\mathbf{1}}$ & $0.9052 \pm 0.0327$ & 0.010954 & $0.9651 \pm 6.12 \times 10^{-3}$ \\
$\boldsymbol{l}_{\mathbf{1}}$ & $3.172 \pm 0.2058$ & $6.072 \pm 0.335$ & $3.164 \pm 0.352$ \\
$\boldsymbol{k}_{\boldsymbol{r} \boldsymbol{2}}$ & $7.833 \times 10^{-14}$ & $1.7998 \times 10^{-14}$ & $3.227 \times 10^{-15}$ \\
$\boldsymbol{m}_{\boldsymbol{2}}$ & 1.1932 & $1.2326 \pm 0.00286$ & $5.644 \pm 0.477$ \\
$\boldsymbol{l}_{\boldsymbol{2}}$ & $4.492 \pm 0.225$ & 0.06163 & $8.697 \pm 0.689$ \\
$\boldsymbol{n}_{\boldsymbol{d}}$ & $1.596 \pm 0.0221$ & $1.797 \pm 0.00123$ & $2.5767 \pm 1.6 \times 10^{-4}$ \\
\hline
\end{tabular}
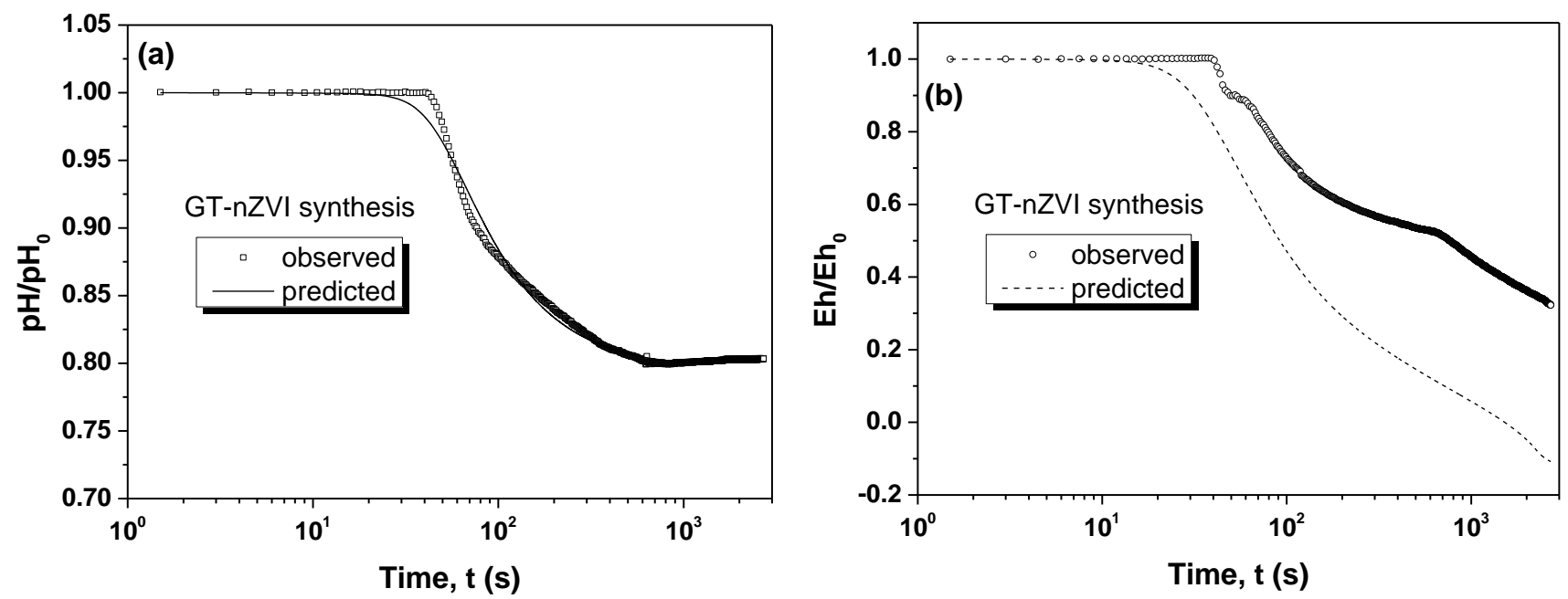

Figure 9. Comparison of experimentally measured with numerically predicted (a) $\mathrm{pH} / \mathrm{pH}$, and (b) $\mathrm{E}_{\mathrm{h}} / \mathrm{E}_{\mathrm{h} 0}$, when ferrous ions are reduced to zero valent iron by the polyphenols of Green Tea extract (GT-nZVI). 

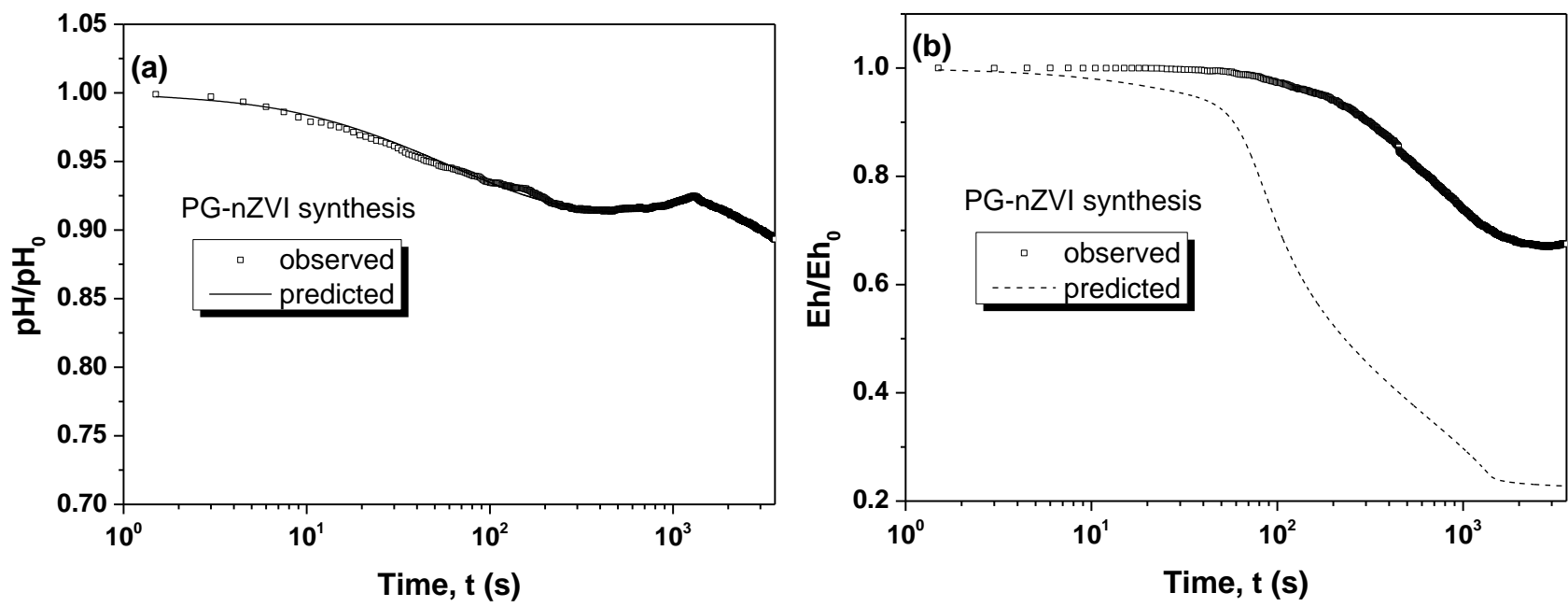

Figure 10. Comparison of experimentally measured with numerically predicted (a) $\mathrm{pH} / \mathrm{pH}$, and (b) $\mathrm{E}_{\mathrm{h}} / \mathrm{E}_{\mathrm{h} 0}$, when ferrous ions are reduced to zero valent iron by the polyphenols of Pomegranate extract (PG-nZVI).
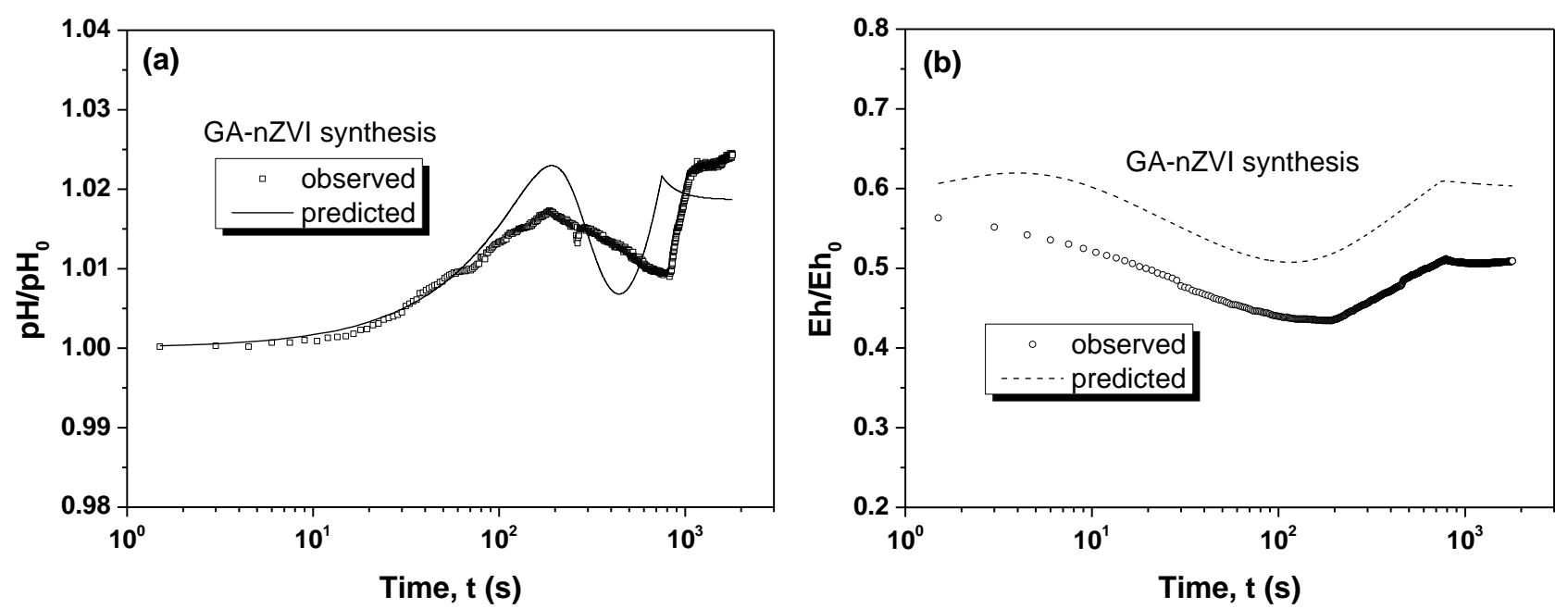

Figure 11. Comparison of experimentally measured with numerically predicted (a) pH/pH0, and (b) Eh/Eh0, when ferrous ions are reduced to zero valent iron by the Gallic Acid (GA-nZVI).
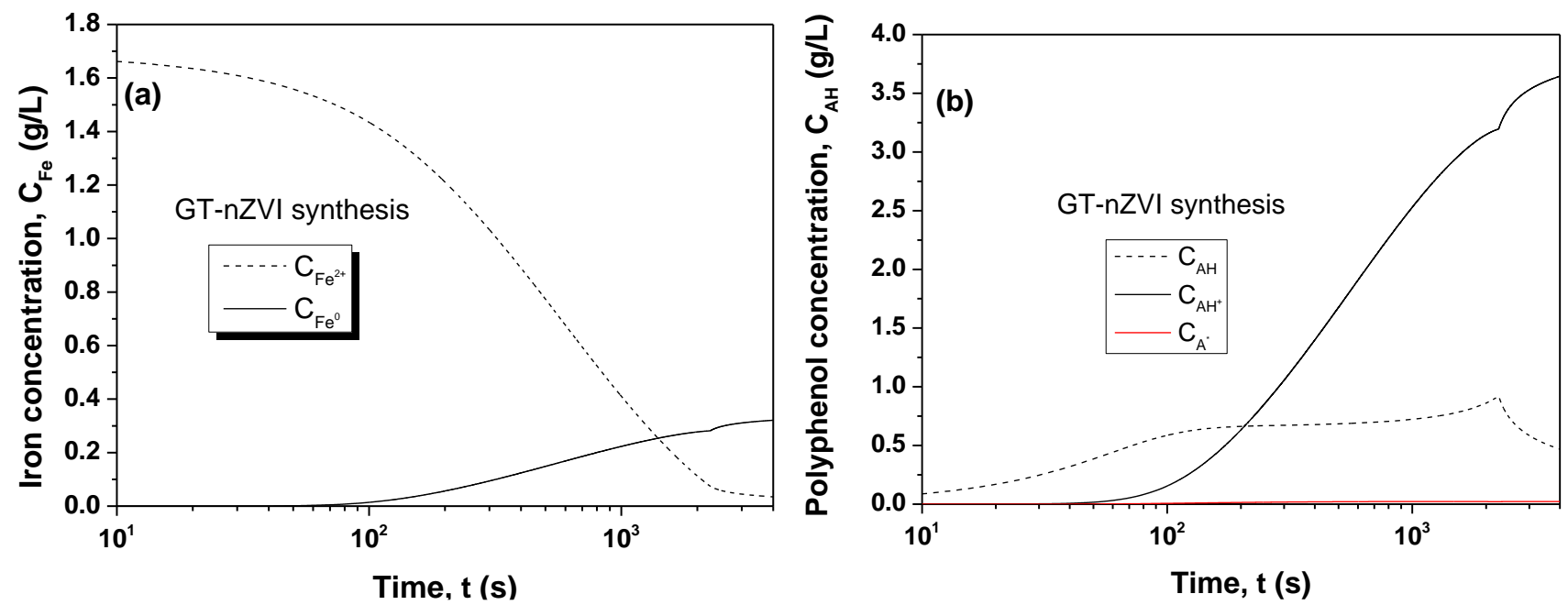

Figure 12. Numerically predicted transient responses of the concentration of (a) iron species, (b) polyphenol species, during the GT-nZVI synthesis. 
Table 5. Final component concentrations and yield (Yi) of ZVI synthesis.

\begin{tabular}{cccc}
\hline Variable & GT-nZVI & PG-nZVI & GA-nZVI \\
\hline $\boldsymbol{t}_{\boldsymbol{m a x}}(\mathrm{s})$ & 4000 & 3600 & 2500 \\
$\boldsymbol{V}_{\boldsymbol{m a x}}(\mathrm{mL})$ & 190 & 122 & 55 \\
$\boldsymbol{C}_{\boldsymbol{F} \boldsymbol{e}^{2+}}(\mathrm{g} / \mathrm{L})$ & 0.03484 & 0.25684 & 1.556 \\
$\boldsymbol{C}_{\boldsymbol{A H}}(\mathrm{g} / \mathrm{L})$ & 0.46881 & 0.40793 & 0.4273 \\
$\boldsymbol{C}_{\boldsymbol{H}^{+}}(\mathrm{g} / \mathrm{L})$ & $7.933 \times 10^{-5}$ & $2.452 \times 10^{-4}$ & $1.97 \times 10^{-3}$ \\
$\boldsymbol{C}_{\boldsymbol{A \boldsymbol { H } ^ { + }}}(\mathrm{g} / \mathrm{L})$ & 3.6454 & 4.855 & 5.833 \\
$\boldsymbol{C}_{\boldsymbol{A}^{*}}(\mathrm{~g} / \mathrm{L})$ & 0.02263 & 0.05787 & 0.1215 \\
$\boldsymbol{C}_{\boldsymbol{F} \boldsymbol{e}^{\mathbf{0}}}(\mathrm{g} / \mathrm{L})$ & 0.32095 & 0.42989 & 0.9818 \\
$\boldsymbol{Y}_{\boldsymbol{A} \boldsymbol{H}^{+}}$ & 0.8812 & 0.9124 & 0.914 \\
$\boldsymbol{Y}_{\boldsymbol{A}^{*}}$ & 0.0055 & 0.0108 & 0.0190 \\
$\boldsymbol{Y}_{\boldsymbol{F} \boldsymbol{e}^{\mathbf{0}}}$ & 0.9020 & 0.6243 & 0.3870 \\
\hline
\end{tabular}

In the case of GT-nZVI synthesis, a significant percentage of the iron mass ( $90 \%)$ has been converted to zero valent iron (Figure 12a, Table 5). Regarding the selectivity of synthesis reactions, only a very small percentage of polyphenol mass reacts according to HAT mechanism, Equation 2, while its highest percentage seems to react in accordance with SET mechanism, Equation 1 (Figure 12b, Table 5). Though the pH is stabilized quickly (Figure 9a), both the redox potential (Figure 9b) and the concentrations of iron (Figure 12a) and polyphenol (Figure 12b) species have the tendency to change even at long reaction times.
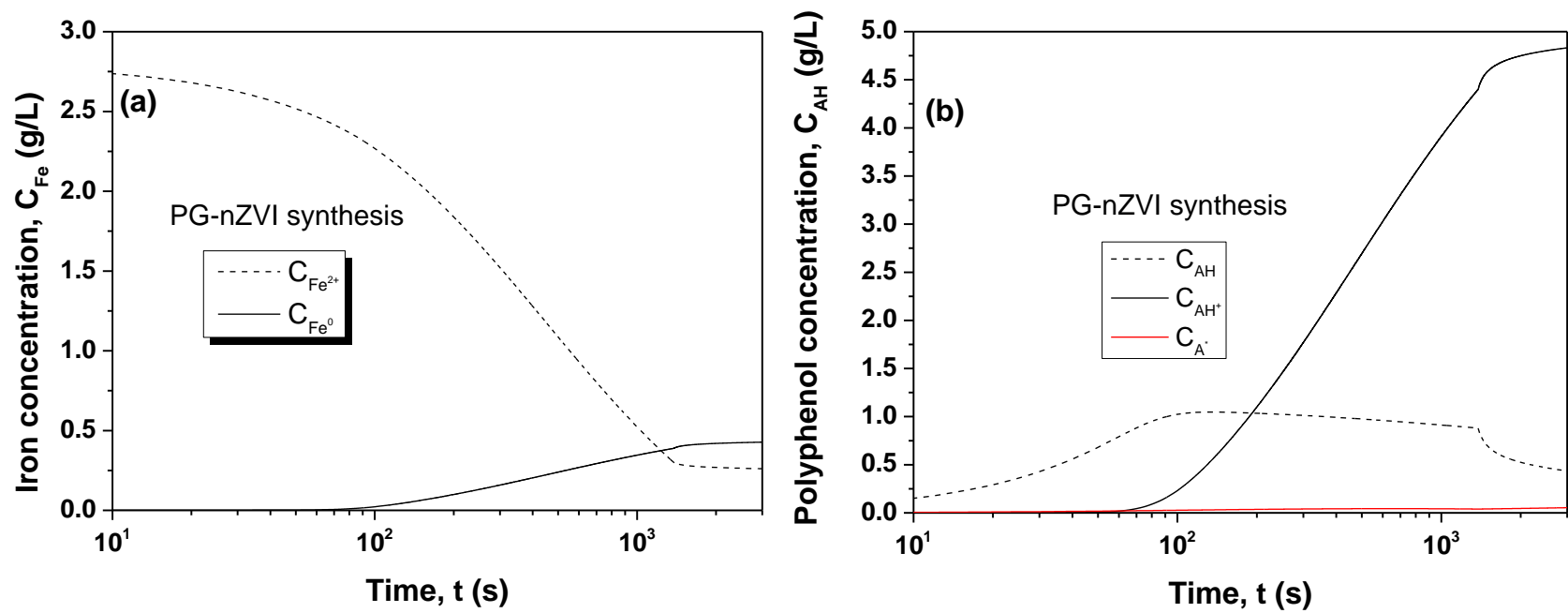

Figure 13. Numerically predicted transient responses of the concentration of (a) iron species, (b) polyphenol species, during the PG-nZVI synthesis

In the case of PG-nZVI synthesis, more than half of the initial ferrous concentration $(\sim 63 \%)$ is reduced to zero valence at late times (Figure 13a, Table 5). Likewise, the SET mechanism, Equation 1, is the dominant one governing the kinetics of polyphenol transformation (Figure 13b). The redox potential (Figure 10b) has the tendency to stabilize at long times, whereas a similar behavior is confirmed also for the concentrations of iron (Figure 13a) and polyphenol (Figure 13b) species. 

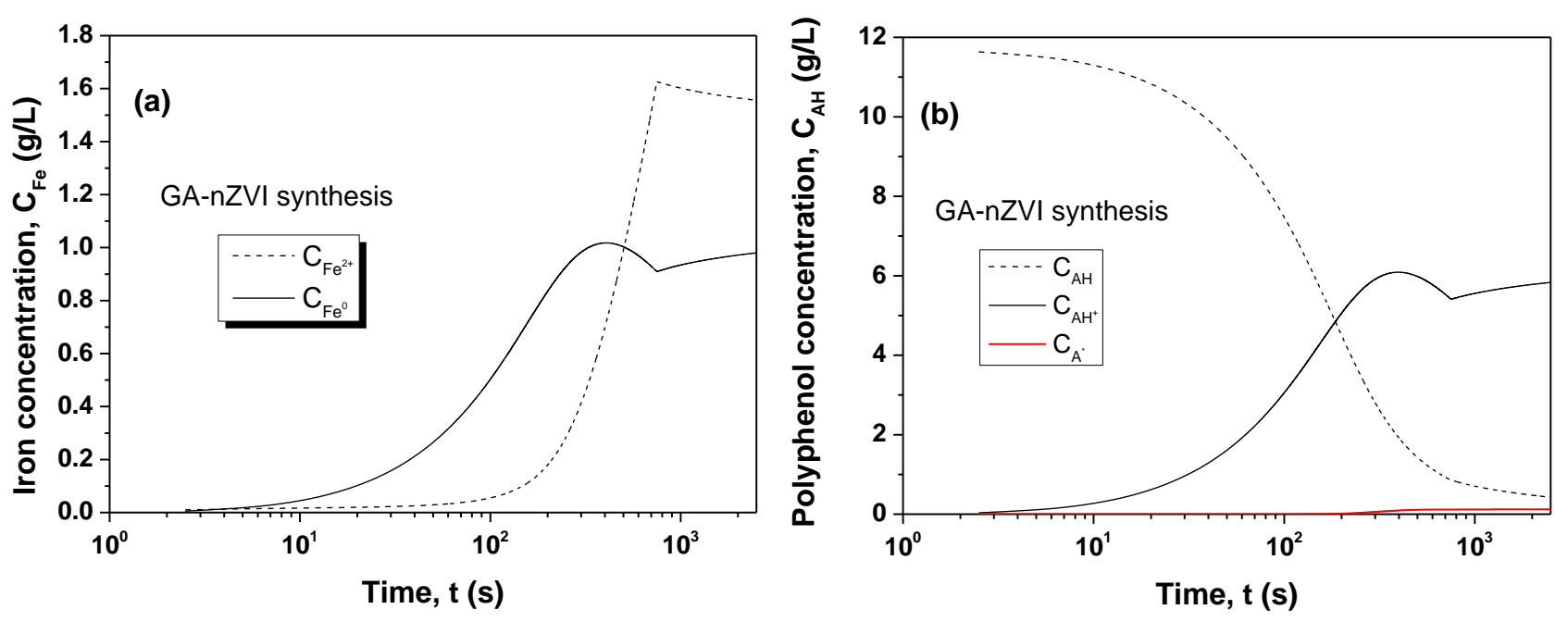

Figure 14. Numerically predicted transient responses of the concentration of (a) iron species, (b) polyphenol species, during the GA-nZVI synthesis

As the iron salt solution is injected in the Gallic Acid solution, the ferrous ions are reduced instantaneously in zero valent iron, which is the only form of iron detected at early times of the mixing process (Figure 14a). Gradually, the production rate of ZVI vanishes, and the concentration of ferrous ions increases, becoming sensible at late stage of the process (Figure 14a). The transient profile of the concentration of GA cations, generated by the SET mechanism, Equation 1, is fully compatible with that of ZVI (Figure 14a and 14b), whereas a small fraction of GA reacts according to the HAT mechanism, Equation 2, (Figure 14b) and this is reflected in the weak change of pH during the synthesis (Figure 11a). On the other hand, less than $50 \%$ of the available iron mass ( 38\%) is converted into ZVI (Table 5).

The yield of reactions, Equations 1 and 2, calculated from the numerical simulations of $\mathrm{Fe}^{0}$ synthesis, at estimated parameter values (Figures 12a and 13a, Table 5), was used to compute the initial concentration of nZVI for the Cr (VI) reduction tests. For each type of nZVI suspension (GT-nZVI, PG-nZVI) a set of three experiments conducted at different initial nZVI concentrations (Figures $8 \mathrm{a}$ and $8 \mathrm{~b}$ ) were fitted simultaneously to the numerical solution of Equations $14 \mathrm{a}$ and $14 \mathrm{~b}$ for estimating the kinetic constant $k_{r, C r}$ (Table 6). Due to the fast reduction of Cr (VI) by GA-nZVI at the highest Fe/Cr mass ratios (Figure 8c), very limited datasets were available, and the kinetic parameter was not estimated for this GA-nZVI system. Accounting for the broad confidence interval of estimated parameter, and the relatively small number of experimental datasets (Figures $8 \mathrm{a}$ and $8 \mathrm{~b}$ ), it seems that the reduction potential is comparable for GT-nZVI and PG-nZVI systems (Table 6).

Table 6. Kinetics of $\mathrm{Cr}$ (VI) reduction by nZVI

\begin{tabular}{cc}
\hline Type of nZVI suspension & $\boldsymbol{k}_{\boldsymbol{r}, \boldsymbol{C r}}\left(\mathbf{m}^{\mathbf{3}} \mathbf{k g}^{-1} \mathbf{s}^{-1}\right)$ \\
\hline GT-nZVI & $0.00768 \pm 0.003963$ \\
PG-nZVI & $0.00599 \pm 0.007885$ \\
\hline
\end{tabular}

\section{5- Conclusion}

Green tea and pomegranate leaves extracts along with Gallic Acid were used to synthesize nanoscale Zero Valent Iron (GT-nZVI , PG-nZVI, GA-nZVI) and use them for hexavalent chromium reduction in aqueous solutions. A twomechanism (SET, HAT) reaction kinetic model was developed to quantify the dynamics of ferrous ion reduction to zero Valent iron and interpret the experimentally observed behavior. The transient responses of $\mathrm{pH}$ were used to estimate the kinetic parameters for each reactive system that control the synthesis process. The main conlcusions are outlined below

- Zero Valent Iron nanoparticles were synthesized from each type of plant extract and Gallic Acid;

- The kinetic parameters of the reaction model were estimated with inverse modeling of $\mathrm{pH}$;

- The redox potential measured during the nZVI synthesis agreed qualitatively with the numerical predictions at estimated parameter values;

- Numerical predictions indicate that SET was the dominant mechanism of ferrous ions reduction to zero valence by polyphenols;

- Comparable $\mathrm{Cr}(\mathrm{VI})$ reduction efficiency was achieved by the two types (GT-nZVI, PG-nZVI) of suspensions, while the highest rates of $\mathrm{Cr}(\mathrm{VI})$ reduction were attained by GA-nZVI. 


\section{6- Funding and Acknowledgments}

We acknowledge support of this work by the project "Innovative Actions in Environmental Research and Development (PErAn)" (MIS 5002358) which is implemented under the "Action for the Strategic Development on the Research and Technological Sector", funded by the Operational Program "Competitiveness, Entrepreneurship and Innovation" (NSRF 2014-2020) and co-financed by Greece and the European Union (European Regional Development Fund).

\section{7- Conflict of Interest}

The author declares that there is no conflict of interests regarding the publication of this manuscript. In addition, the ethical issues, including plagiarism, informed consent, misconduct, data fabrication and/or falsification, double publication and/or submission, and redundancies have been completely observed by the authors.

\section{8- References}

[1] Taghizadeh, Maryam, Daryoush Yousefi Kebria, Gholamreza Darvishi, and Farshad Kootenaei. "The Use of Nano Zero Valent Iron in Remediation of Contaminated Soil and Groundwater." International Journal of Scientific Research in Environmental Sciences 1 (2013): 152-57.

[2] Kharissova, Oxana V., H.V. Rasika Dias, Boris I. Kharisov, Betsabee Olvera Pérez, and Victor M. Jiménez Pérez. "The Greener Synthesis of Nanoparticles.” Trends in Biotechnology 31, no. 4 (April 2013): 240-248. doi:10.1016/j.tibtech.2013.01.003.

[3] Karn, Barbara, Todd Kuiken, and Martha Otto. "Nanotechnology and in Situ Remediation: A Review of the Benefits and Potential Risks." Ciencia \& Saude Coletiva 16, no. 1 (January 2011): 165-78.

[4] Matlochova, Adela, Daniela Placha, and Nada Rapantova. "The Application of Nanoscale Materials in Groundwater Remediation." Polish Journal of Environmental Studies 22 (2013): 1401-10.

[5] Tratnyek, Paul G., and Richard L. Johnson. "Nanotechnologies for Environmental Cleanup.” Nano Today 1, no. 2 (May 1, 2006): 44-48. doi:10.1016/S1748-0132(06)70048-2.

[6] Rajan, C.S. Rajan. "Nanotechnology in Groundwater Remediation." International Journal of Environmental Science and Development 2, no. 3 (2011): 182-87. doi:10.7763/IJESD.2011.V2.121.

[7] T. Satyanarayana, and S.Sudhakar Reddy. "A Review on Chemical and Physical Synthesis Methods of Nanomaterials." International Journal for Research in Applied Science \& Engineering Technology 6, no. 1 (2018): 2885-89.

[8] Rajput N. "Methods of Preparation of Nanoparticles." International Journal of Advances in Engineering \& Technology 7, no. 6 (2013): 1806-11. doi:10.1016/j.jare.2015.02.007.

[9] Machado, S., S. L. Pinto, J. P. Grosso, H. P A Nouws, J. T. Albergaria, and C. Delerue-Matos. "Green Production of Zero-Valent Iron Nanoparticles Using Tree Leaf Extracts." Science of the Total Environment 445-446 (February 15, 2013): 1-8. doi:10.1016/j.scitotenv.2012.12.033.

[10] Li, Xiao-qin, Daniel W Elliott, and Wei-xian Zhang. "Zero-Valent Iron Nanoparticles for Abatement of Environmental Pollutants: Materials and Engineering Aspects." Critical Reviews in Solid State and Materials Sciences 31, no. 4 (2006): 111-22. doi:10.1080/10408430601057611.

[11] Hoag, George E., John B. Collins, Jennifer L. Holcomb, Jessica R. Hoag, Mallikarjuna N. Nadagouda, and Rajender S. Varma. “Degradation of Bromothymol Blue by 'greener' Nano-Scale Zero-Valent Iron Synthesized Using Tea Polyphenols." Journal of Materials Chemistry 19, no. 45 (November 10, 2009): 8671-77. doi:10.1039/b909148c.

[12] Saif, Sadia, Arifa Tahir, and Yongsheng Chen. "Green Synthesis of Iron Nanoparticles and Their Environmental Applications and Implications.” Nanomaterials (Basel, Switzerland) 6, no. 11 (November 12, 2016). doi:10.3390/nano6110209.

[13] Machado, S., S.L. Pinto, J.P. Grosso, H.P.A. Nouws, J.T. Albergaria, and C. Delerue-Matos. "Green Production of Zero-Valent Iron Nanoparticles Using Tree Leaf Extracts." Science of The Total Environment 445-446 (February 15, 2013): 1-8. doi:10.1016/j.scitotenv.2012.12.033.

[14] Mystrioti, C., D. Sparis, N. Papasiopi, A. Xenidis, D. Dermatas, and M. Chrysochoou. "Assessment of Polyphenol Coated Nano Zero Valent Iron for Hexavalent Chromium Removal from Contaminated Waters." Bulletin of Environmental Contamination and Toxicology 94, no. 3 (March 16, 2015): 302-7. doi:10.1007/s00128-014-1442-z.

[15] Wang, Ting, Jiajiang Lin, Zuliang Chen, Mallavarapu Megharaj, and Ravendra Naidu. "Green Synthesized Iron Nanoparticles by Green Tea and Eucalyptus Leaves Extracts Used for Removal of Nitrate in Aqueous Solution." Journal of Cleaner Production 83 (November 15, 2014): 413-19. doi:10.1016/J.JCLEPRO.2014.07.006. 
[16] Lin, Jiewen, Xiulan Weng, Rajarathnam Dharmarajan, and Zuliang Chen. "Characterization and Reactivity of Iron Based Nanoparticles Synthesized by Tea Extracts under Various Atmospheres.” Chemosphere 169 (February 1, 2017): 413-17. doi:10.1016/J.CHEMOSPHERE.2016.11.092.

[17] Xin, Haiyan, Xin Yang, Xiaoli Liu, Xueping Tang, Lianjin Weng, and Yuanyuan Han. "Biosynthesis of Iron Nanoparticles Using Tie Guanyin Tea Extract for Degradation of Bromothymol Blue.” Journal of Nanotechnology 2016 (December 27, 2016): 1-8. doi:10.1155/2016/4059591.

[18] Manquián-Cerda, Karen, Edgardo Cruces, María Angélica Rubio, Camila Reyes, and Nicolás Arancibia-Miranda. "Preparation of Nanoscale Iron (Oxide, Oxyhydroxides and Zero-Valent) Particles Derived from Blueberries: Reactivity, Characterization and Removal Mechanism of Arsenate." Ecotoxicology and Environmental Safety 145 (November 2017): 69-77. doi:10.1016/j.ecoenv.2017.07.004.

[19] Rosales, Emilio, M. Ángeles Sanromán, and Celia Dias-Ferreira. “Green Zero-Valent Iron Nanoparticles Synthesized Using Herbal Extracts for Degradation of Dyes from Wastewater.” DESALINATION AND WATER TREATMENT 92 (2017): 15967. doi:10.5004/dwt.2017.20713.

[20] Poguberovi , S. S., D. M. Kr mar, B. D. Dalmacija, S. P. Maleti , D. D. Toma evi -Pilipovi , D. V. Kerkez, and S. D. Ron evi . "Removal of $\mathrm{Ni}(\mathrm{II})$ and $\mathrm{Cu}(\mathrm{II})$ from Aqueous Solutions Using 'green Zero-Valent Iron Nanoparticles Produced by Oak and Mulberry Leaf Extracts.” Water Science and Technology 74, no. 9 (November 14, 2016): 2115-23. doi:10.2166/wst.2016.387.

[21] Machado, S, J G Pacheco, H P A Nouws, J T Albergaria, and C Delerue-Matos. "Characterization of Green Zero-Valent Iron Nanoparticles Produced with Tree Leaf Extracts." Science of The Total Environment 533 (2015): 76-81. doi:https://doi.org/10.1016/j.scitotenv.2015.06.091.

[22] Rao, Ashit, Ketakee Mahajan, Ashok Bankar, Rapole Srikanth, Ameeta Ravi Kumar, Suresh Gosavi, and Smita Zinjarde. "Facile Synthesis of Size-Tunable Gold Nanoparticles by Pomegranate (Punica Granatum) Leaf Extract: Applications in Arsenate Sensing." Materials Research Bulletin 48, no. 3 (March 1, 2013): 1166-73. doi:10.1016/J.MATERRESBULL.2012.12.025.

[23] Makarov, V V, A J Love, O V Sinitsyna, S S Makarova, I V Yaminsky, M E Taliansky, and N O Kalinina. ““Green' Nanotechnologies: Synthesis of Metal Nanoparticles Using Plants.” Acta Naturae, 2014.

[24] EPA, United States Environmental Protection Agency. "Method 7196A." Chromium, Hexavalente (Colorimetric), no. July (1992): 1-6.

[25] Karamac, Magdalena, Agnieszka Kosinska, and Ronald Pegg. "Content of Gallic Acid in Selected Plant Extracts.” Polish Journal of Food and Nutrition Sciences 15, no. 1 (2006): 55-58.

[26] Lith, Robert van, and Guillermo A. Ameer. “Antioxidant Polymers as Biomaterial.” Oxidative Stress and Biomaterials, January 1, 2016, 251-96. doi:10.1016/B978-0-12-803269-5.00010-3.

[27] Layek, Arunasish, Gargi Mishra, Archana Sharma, Marina Spasova, Subhabrata Dhar, Arindam Chowdhury, and Rajdip Bandyopadhyaya. “A Generalized Three-Stage Mechanism of ZnO Nanoparticle Formation in Homogeneous Liquid Medium.” Journal of Physical Chemistry C 116, no. 46 (November 26, 2012): 24757-69. doi:10.1021/jp211613b.

[28] Prior, Ronald L., Xianli Wu, and Karen Schaich. "Standardized Methods for the Determination of Antioxidant Capacity and Phenolics in Foods and Dietary Supplements." Journal of Agricultural and Food Chemistry, May 18, 2005. doi:10.1021/jf0502698.

[29] Stewart, Warren E., and Michael. Caracotsios. Computer-Aided Modeling of Reactive Systems. Hoboken,New Jersey: WileyInterscience, 2008.

[30] Kumar, R., N. Singh, and S. N. Pandey. "Potential of Green Synthesized Zero-Valent Iron Nanoparticles for Remediation of Lead-Contaminated Water.” International Journal of Environmental Science and Technology 12, no. 12 (December 14, 2015): 3943-50. doi:10.1007/s13762-015-0751-z.

[31] R SenthilkumarT, S, Sivakumar Thirumal, Ks Arulmozhi, and N.Mythili. "FT-IR Analysis and Correlation Studies on the Antioxidant Activity, Total Phenolics and Total Flavonoids of Indian Commercial Teas (." International Research Journal of Biological Sciences 6 (2017): 1-7.

[32] Park, Yong-Seo, Mi-Kyung Lee, Buk-Gu Heo, Kyung-Sik Ham, Seong-Gook Kang, Ja-Yong Cho, and Shela Gorinstein. "Comparison of the Nutrient and Chemical Contents of Traditional Korean Chungtaejeon and Green Teas." Plant Foods for Human Nutrition 65, no. 2 (June 21, 2010): 186-91. doi:10.1007/s11130-010-0170-8.

[33] Eddebbagh, Malak, Abdelmjid Abourriche, Mohamed Berrada, Mourad Ben Zina, and Ahmed Bennamara. "Adsorbent Material from Pomegranate (Punica Granatum) Leaves: Optimization on Removal of Methylene Blue Using Response Surface Methodology.” Journal of Materials and Environmental Science 7, no. 6 (2016): 2021-33. 
[34] Nisha, M Haniff, R Tamileswari, Sr S Jesurani, S Kanagesan, M Hashim, and S Catherine P Alexander. "Green Synthesis of Silver Nanoparticles From Pomegranate (Punicagranatum) Leaves and Analysis of Anti-Bacterial Activity." International Journal of Advanced Technology in Engineering and Science 4, no. 03 (2015): 1-8.

[35] Kannan, R R R, R Arumugam, and P Anantharaman. "Fourier Transform Infrared Spectroscopy Analysis of Seagrass Polyphenols." Current Bioactive Compounds 7, no. 2 (2011): 118-25.

[36] Hirun, Namon, Supaporn Dokmaisrijan, and Vimon Tantishaiyakul. "Experimental FTIR and Theoretical Studies of Gallic AcidAcetonitrile Clusters." Spectrochimica Acta Part A: Molecular and Biomolecular Spectroscopy 86 (February 1, 2012): 93-100. doi:10.1016/J.SAA.2011.10.009.

[37] S Oakes, Jacqueline. "Investigation of Iron Reduction by Green Tea Polyphenols for Application in Soil Remediation." University of Connecticut, 2013. 